\title{
JARDIM SENSORIAL: DISCUTINDO CONCEITOS DE GEOGRAFIA FÍSICA
}

\author{
Renata de Azevedo Tavares Guedes ${ }^{(a)}$ Roberta Maria Rodrigues Gomes ${ }^{(b)}$ Tatiana Cordeiro de

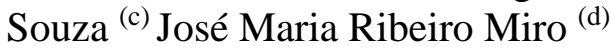

(a) Instituto Federal Fluminense, renataaztavaresg@ hotmail.com

(b) Instituto Federal Fluminense, tatianacs.08@ gmail.com

(c) Instituto Federal Fluminense, roberta.rodrigues9093@ yahoo.com.br

(d) Instituto Federal Fluminense, jmiro.geo@ hotmail.com

\section{EIXO: GEOGRAFIA FÍSICA: CURRÍCULO, FORMAÇÃO E PRÁTICAS DE ENSINO}

\begin{abstract}
Resumo
Neste trabalho, foram realizadas aulas de campo no Jardim Sensorial, um projeto desenvolvido pelo IFF Campos em parceria com a secretaria de Desenvolvimento Ambiental e fisicamente localizado no Centro de Educação Ambiental (CEA) da prefeitura de Campos dos Goytacazes, onde se discute conteúdos relacionados à questão ambiental. $\mathrm{O}$ trabalho de campo foi considerado instrumento de ensino importante no aprendizado em várias áreas do conhecimento. Sua construção deve corresponder às expectativas dos professores na transposição de conteúdos, sendo local de descoberta e aproximação do ambiente visitado, para que o aluno possa vivenciar a teoria e a prática. Os resultados mostram a mudança de entendimento dos alunos com relação aos conteúdos discutidos e a importância da participação dos professores para o bom êxito das atividades.
\end{abstract}

Palavras-chaves: Geografia física. Ensino. Conceitos

\section{Introdução}

Esta pesquisa faz parte de um projeto desenvolvido pelo Instituto Federal de Educação, Ciência e Tecnologia Fluminense (IFF) em parceria com a Secretaria de Desenvolvimento Ambiental do município de Campos dos Goytacazes - RJ. Fisicamente suas atividades acontecem no Centro de Educação Ambiental (CEA) da prefeitura, onde desde 2012 recebe estudantes do Ensino Básico para discutir conteúdos relacionados à questão ambiental.

Suas atividades são organizadas para que funcionem como instrumento de ensino aprendizagem em várias áreas do conhecimento, mas principalmente de Geografia. Na sua construção pretende-se corresponder às expectativas que considere o espaço visitado como essencial para a transposição de conteúdos, um espaço de descoberta e aproximação do ambiente, onde o aluno possa vivenciar a teoria e a prática. Este projeto analisa objetos contidos na relação entre o homem e a natureza e as inter-relações dos fenômenos socioambientais dos conteúdos curriculares (PAES et al., 2013).

O CEA, local onde se realiza as aulas, é considerado um espaço não formal de ensino, onde as atividades ocorrem fora das unidades de educação regular, similares aos museus, praças, jardins botânicos, áreas de preservação, teatros, etc. Desta forma, "oferece uma didática estimulante, que atrai os alunos para as 
discussões, na direção de formar cidadãos mais críticos, que questionem o mundo a sua volta, o espaço vivido e seus valores culturais" (JACOBUCCI, p. 56, 2008).

"Segundo Paes (2014) Jardim Sensorial é um lugar que propõe reconhecer a natureza de outra maneira, por meio das texturas das folhas, do cheiro, do som, para tanto estimulando a utilização dos outros sentidos além da visão, favorecendo também pessoas com deficiência".

O Jardim Sensorial é um instrumento para práticas de ensino não formal entendido como um espaço interdisciplinar, pois, é possível trabalhar diversas disciplinas e conteúdos, integrar os diferentes sentidos dos alunos, uma vez que o mundo é extremamente vasto, suas formas de vida e tudo que nos cerca desperta o interesse em conhecê-lo. Como nos conta TUAN (1974), a maneira pela qual se percebe o que está a nossa volta é singular, onde cada indivíduo percebe uma realidade, mesmo quando compartilha o mesmo espaço, o que pode resultar numa Percepção Ambiental diferente.

Coloquialmente, a natureza é conceituada como um mundo natural ou mundo físico. Na Antiguidade era vista e entendida como algo místico. Hoje, com um olhar mais científico, ela é tida como um contexto estrutural, para entender a totalidade do espaço ocupado pela sociedade, onde o ser humano pode alterar sua forma, estrutura, processos e funções, pois modifica o meio natural através do trabalho, utiliza elementos naturais para a ampliação e modificação do espaço, constituindo-se num agente modificador do espaço (SANTOS, 2006, p. 84).

Neste trabalho, os jardins são entendidos como ambientes naturais controlados, ou seja, uma natureza construída pelo homem. Por isso, o objetivo foi à compreensão dos alunos sobre as diferenças entre os conceitos de Natureza e Jardim, discutidos através de técnicas lúdicas diversificadas, onde os conteúdos são trabalhados visando sua melhor compreensão na sala de aula formal.

\section{Materiais e Métodos}

Esta pesquisa foi realizada com estudantes de seis turmas do Ensino Fundamental I, totalizando 84 alunos, da Escola Municipal Custódio Siqueira, localizada no município de Campos dos Goytacazes/RJ. Na aula de campo no Jardim Sensorial, as atividades foram divididas em três partes: Pré-Campo - entrevista com o professor responsável pela turma, informando-o sobre todas as atividades e elaboração de desenho pelos alunos sobre o que eles entendem por Jardim; Campo - quando são realizadas as atividades no Jardim Sensorial, utilizando dinâmicas como: a cabra-cega (os alunos são vendados para utilizarem os seus outros sentidos e identificarem o ambiente a sua volta), jogos dos erros (momento de colocar alguns objetos artificiais no jardim, para que os alunos os diferenciem); Pós-campo - os alunos desenham novamente, para assim saber se houve mudança no entendimento dos conceitos de jardim e natureza. 


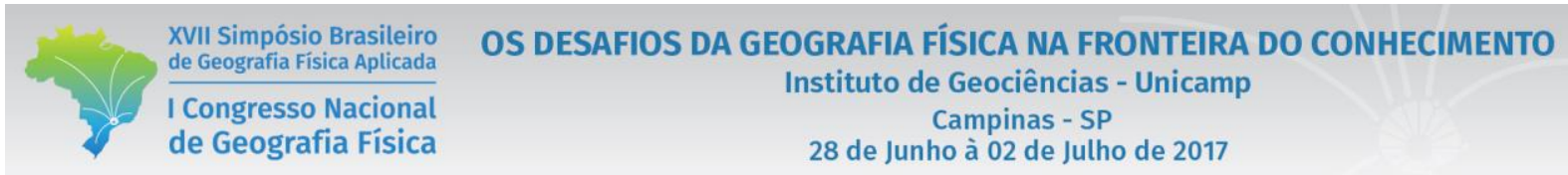

Desta forma, mediu-se a compreensão dos alunos referente aos conceitos, utilizando o Método da Percepção Ambiental como parâmetro de análise e embasamento teórico das discussões relativas a manifestações de processos cognitivos, sensoriais, psicológicos e de aprendizagem acerca do ambiente (TUAN, 1980). Este trabalho valorizou o uso dos cinco sentidos para que os alunos identificassem de que forma podem-se usar todos eles e que é possível à utilização e o aprimoramento de cada um na descoberta diária do ambiente. Na Figura 1 observam-se as etapas da atividade.

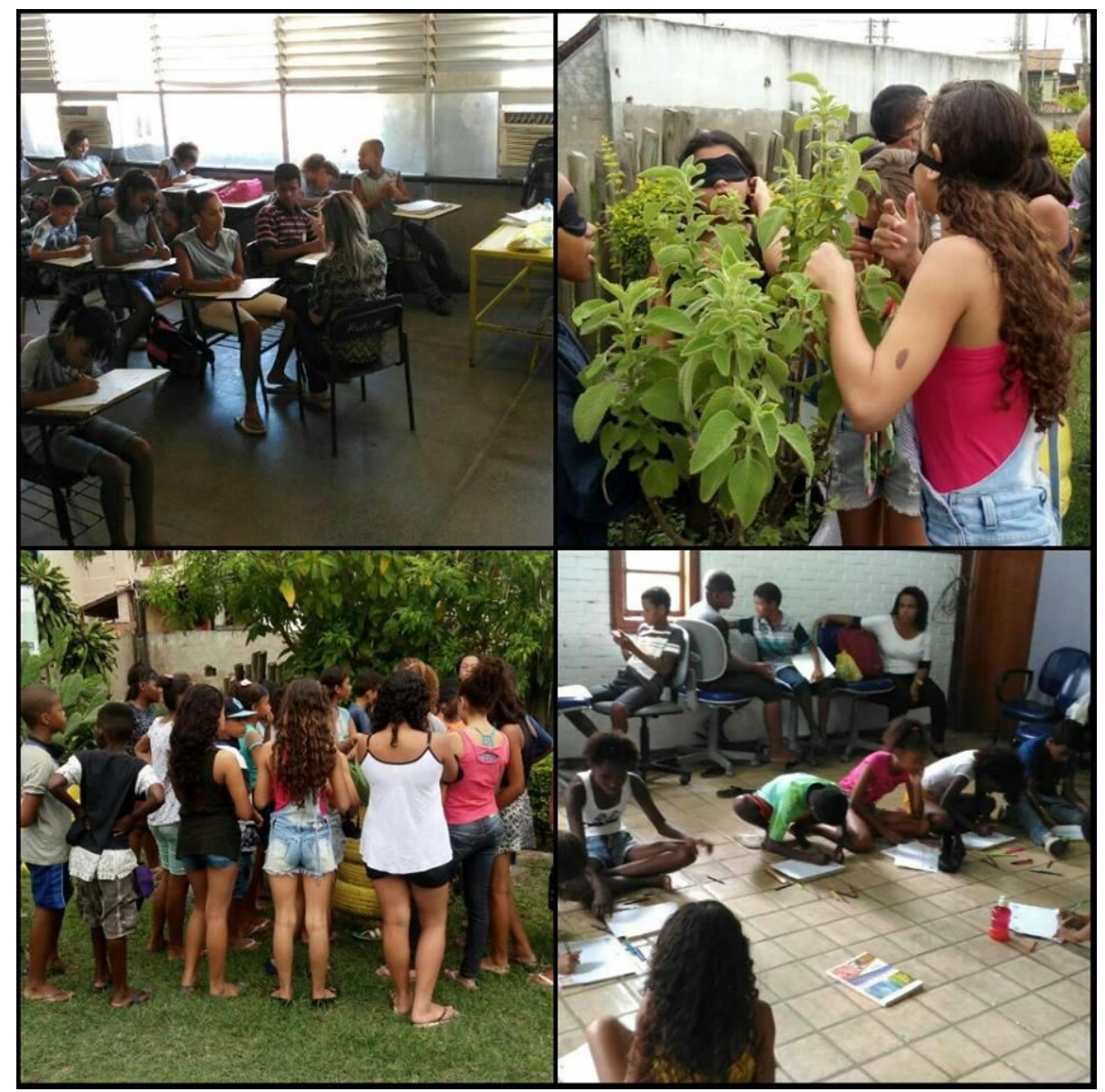

Figura 1- Etapas da aula de campo

Isto é possível porque os alunos constroem mapas mentais sobre os conteúdos discutidos em sala de aula e o cotidiano vivenciado por cada um. Logo, "esta representação foi considerada instrumento que possibilita a descrição das experiências obtidas, podendo expressá-las de forma espontânea ou através de expressões gráficas como desenhos" (PONTUSCHKA et al., 2009, p. 314). 


\section{Resultados e Discussões}

Para a análise dos desenhos elaborados pelos alunos antes e após a aula de campo, os dados foram organizados em dois gráficos: um sobre a quantidade dos elementos naturais desenhados pelos discentes; e outro sobre os elementos artificiais presentes. Assim, pode-se perceber o que eles entendiam por jardim antes e se sua concepção mudou após a atividade.

Os resultados obtidos mostram que os alunos desenharam mais elementos naturais antes e depois do campo, comparados com os elementos artificiais, porém, ressalta-se que os elementos artificiais desenhados após a aula quase dobraram de número. Desta forma, percebe-se que os alunos, conseguiram entender que jardim não é sinônimo de natureza, e que há influência humana.

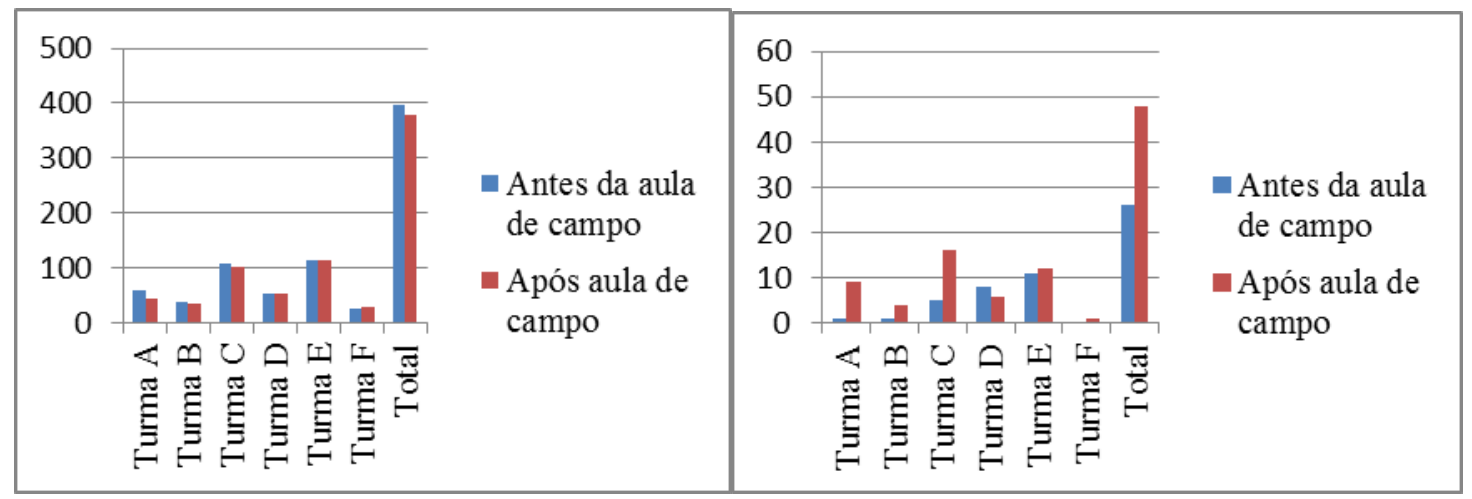

Figura 2 - Elementos Naturais

Figura 3 - Elementos Artificiais

Houve uma diminuição dos elementos naturais desenhados pelos alunos após a aula, porém, eles ainda os desenharam. Os elementos artificiais $31 \%(\mathrm{n}=26)$ foram desenhados antes da atividade e $57 \%(\mathrm{n}=48)$ depois. Isso mostra que o entendimento de jardim para os alunos era semelhante ao conceito de natureza. Contudo os alunos entenderam que há presença de elementos artificiais no jardim.

Ressalta-se, que os elementos naturais mais desenhados pelos alunos foram: sol, árvores, plantas, nuvens e animais, ou seja, elementos presentes em seu cotidiano, no qual se tem proximidade, e por vezes os confundiam como jardim. Por isso, a maioria dos alunos desenhou somente elementos naturais antes do campo, dessa forma, confundindo o conceito de jardim com natureza.

Além dos resultados já mencionados através dos desenhos, observaram-se particularidades em cada turma/professor, que consequentemente obtiveram diferentes resultados. Desta forma, podem-se destacar duas turmas que tiverem resultados significativos (turma $\mathrm{A}$ e C), ao se comparar com as demais, pois tiveram um maior número de alunos que desenharam elementos artificiais em seus desenhos após o campo, como se vê no exemplo abaixo. 


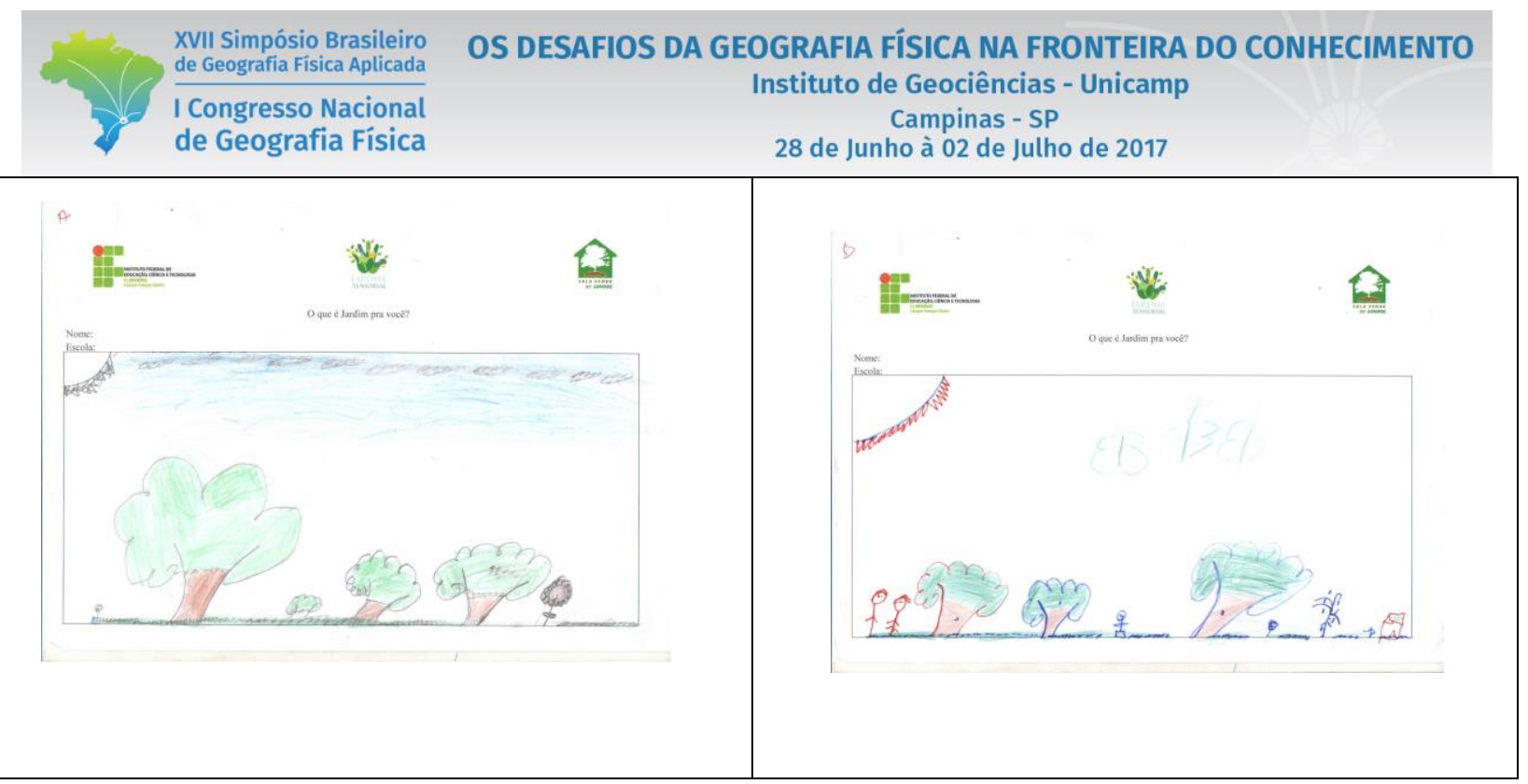

Figura 4 - Desenhos antes e depois da aula de campo.

Em consequência disso, é importante levar em consideração a participação dos professores durante as aulas de campo, pois nota-se que as turmas que obtiveram os melhores resultados são aquelas que tiveram maior envolvimento do professor titular. Assim, pode-se afirmar que como qualquer instrumento didático, é imprescindível a participação dos professores, para se alcançar melhores resultados.

\section{Conclusão}

Aulas realizadas em espaços não formais de ensino, como o Jardim Sensorial, facilitam a compreensão de determinados conceitos pelos alunos, como jardim e natureza. Além de tornar a aula mais atrativa, e ter maior interesse dos participantes. Pode-se concluir, também, que a participação dos professores titulares é importante para se obter melhores resultados com as turmas. Verificou-se que após a realização do Trabalho de Campo no Jardim Sensorial a compreensão dos alunos ficou mais próxima da realidade, quando se analisa os elementos presentes nos desenhos (união de elementos naturais e artificiais).

\section{REFERÊNCIAS}

JACOBUCCI, D. F. C. Contribuições dos espaços não-formais de educação para a formação da cultura científica. Uberlândia: Revista Em Extensão, V. 7, 2008.

LOPES, A. R. C; RICHTER, D. A construção de mapas mentais e o ensino de geografia: Articulações entre o cotidiano e os conteúdos escolares. Revista Eletrônica de Geografia: Territorium terram. V.02, No 03, p.2-12/ out/março, 2013/2014.

PAES, R. da S. et al. Alternativas de transposição de conteúdos em Educação Ambiental: Jardim Sensorial. 65 Reunião Anual da Sociedade Brasileira para o Progresso da Ciência, Recife/PE, 2013.

PAES, R. da S. et al. Jardim Sensorial como espaço não formal de educação em ciências. Encontro Nacional das Licenciaturas. Natal/RN, 2014. 
PAES, R. da S. Jardim sensorial: discutindo conceitos geográficos num espaço não formal de ensino. Instituto Federal de Educação, Ciência e Tecnologia Fluminense. (Monografia) Campos dos Goytacazes/RJ, 2014.

PONTUSCHKA, Nídia Nacib; PAGANELLI, Tomoko Iyda; CACETE, Núria Hanglei. Para ensinar e aprender Geografia. 3.ed, $1^{\text {a }}$ reimpressão. São Paulo: Cortez, 2009.

SANTOS, M. A Natureza do Espaço: Técnica e Tempo, Razão e Emoção. 4.ed, SP, EDUSP, 2006.

TUAN, Y. Topofilia: um estudo da percepção, atitudes e valores do meio ambiente. São Paulo: Difel, 1974. 